\title{
Combining socio-economic and climate projections to assess heat risk
}

\author{
Armand Landreau $^{1,2} \cdot$ Sirkku Juhola $^{2}$ (D) - Alexandra Jurgilevich ${ }^{2}$ (D) \\ Aleksi Räsänen ${ }^{2,3}$ (D)
}

Received: 11 September 2020 / Accepted: 18 June 2021/ Published online: 16 July 2021

(C) The Author(s) 2021

\begin{abstract}
The assessments of future climate risks are common; however, usually, they focus on climate projections without considering social changes. We project heat risks for Finland to evaluate (1) what kind of differences there are in heat vulnerability projections with different scenarios and scales, and (2) how the use of socioeconomic scenarios influences heat risk assessments. We project a vulnerability index with seven indicators downscaled to the postal code area scale for 2050. Three different scenario sets for vulnerability are tested: one with five global Shared Socioeconomic Pathways (SSPs) scenarios; the second with three European SSPs (EUSSPs) with data at the sub-national scale (NUTS2); and the last with the EUSSPs but aggregated data at the national scale. We construct projections of heat risk utilizing climatic heat hazard data for three different Representative Concentration Pathways (RCPs) and vulnerability and exposure data for five global SSPs up to 2100 . In the vulnerability projections, each scenario in each dataset shows a decrease in vulnerability compared to current values, and the differences between the three scenario sets are small. There are evident differences both in the spatial patterns and in the temporal trends when comparing the risk projections with constant vulnerability to the projections with dynamic vulnerability. Heat hazard increases notably in RCP4.5 and RCP8.5, but a decrease of vulnerability especially in SSP1 and SSP5 alleviates risks. We show that projections of vulnerability have a considerable impact on future heat-related risk and emphasize that future risk assessments should include the combination of long-term climatic and socioeconomic projections.
\end{abstract}

Keywords Adaptation $\cdot$ Climate change $\cdot$ Heat risk $\cdot$ Socio-economic scenarios $\cdot$ Vulnerability dynamics

Aleksi Räsänen

aleksi.rasanen@luke.fi

Extended author information available on the last page of the article 


\section{Introduction}

It has been estimated that the 2003 summer heatwave in Europe caused 70,000 excess deaths (Robine et al. 2008). The frequency and intensity of extreme heat events (Dosio et al. 2018) and heat-related mortality (e.g. Marsha et al. 2016; Mora et al. 2017; Chen et al. 2017; Botzen et al. 2020) are projected to increase. In addition to increased mortality, heat causes a wide range of direct adverse impacts on human health, including impacts on cardio-vascular (Sohail et al. 2020), mental (Palinkas and Wong 2020), occupational (Kjellstrom et al. 2016), and maternal (Kuehn and McCormick 2017) health.

Adapting to heat risks most often starts with climate risk or vulnerability assessments. Risk is a function of a climate hazard (i.e. in our study heat), exposure (the presence of an object at risk in places and settings that could be adversely affected; IPCC 2014), and vulnerability ("the propensity or predisposition to be adversely affected"; IPCC 2014, p. 128). It has been shown that socio-economic (i.e. vulnerability and exposure) factors are important drivers of heat risk and can be even more important than hazard (Chen et al. 2018; Rohat et al. 2019b). Relevant socio-economic factors include, e.g., gender, childhood, old age, low income, low education level, social isolation, and health status (Reckien et al. 2017; Räsänen et al. 2019; Rohat et al. 2019a, 2019b).

Climate change risks and vulnerability assessments are increasingly future-oriented since adaptation governance and planning need actionable information about future risks (Adger et al. 2018; Jurgilevich et al. 2017). Often, such assessments include hazard projections, while the incorporation of socio-economic projections has been scarce (Jurgilevich et al. 2017; De Sherbinin et al. 2019). When socio-economic factors of risk are considered, they are mainly used to estimate future exposure but not vulnerability (Jurgilevich et al. 2017). The need to include future vulnerability projections is widely recognized since vulnerability is a dynamic phenomenon (Dilling et al. 2015; Ford et al. 2018). The most common constraints in assessing future vulnerability are high uncertainties in projecting future socio-economic development (Vanos et al. 2020), lack of conceptual clarity, and methodological limitations, most notably the lack of future-oriented socio-economic data at a usable spatial scale (Jurgilevich et al. 2017).

Scenarios are a common method used to capture broader developments and changes (Elsawah et al. 2020). Projections of future risks and vulnerability using emissions scenarios (Representative Concentration Pathways, i.e. RCPs; van Vuuren et al. 2011) and socio-economic scenarios (Shared Socioeconomic Pathways, i.e. SSPs; O’Neill et al. 2013) have become common during the past decade (O'Neill et al. 2020). SSP storylines have enabled the development of national-scale quantitative projections for the population structure, education level, urbanization, and GDP up to 2100 (KC and Lutz 2017; Jiang and O'Neill 2017; Dellink et al. 2017). These data make it possible to quantitatively project exposure and vulnerability in the assessments of heat risk, and empirical studies have used SSPs to assess heat-related mortality (e.g. Botzen et al. 2020; Chen et al. 2017; Marsha et al. 2016; Mora et al. 2017). For example, Botzen et al. (2020) use SSPs to account for age changes in their demographic projections, and Marsha et al. (2016) use SSPs to explore demographic changes including age group changes, social isolation, and household median income. However, most of the time only a few scenarios are used (Marsha et al. 2016; Anderson et al. 2016). Moreover, the SSPs have been criticized for the poor consideration of the local context since they have been narrated on a global scale (van Ruijven et al. 2013). In response to this, the SSPs have been downscaled to a more local scale (e.g. Absar and Preston 2015; Nilsson et al. 2017), and extended SSPs for Europe (EUSSPs) have been developed (Kok et al. 2018; Rohat et al. 2018). So far, only one study has constructed a heat risk index using these scenarios (Rohat et al. 2019a), and 
no one has projected a heat risk index over the entire century, although this type of projection has been used to project the impact of global sea level rise (Nauels et al. 2017; Nishiura et al. 2020). Furthermore, the projections of regional SSPs, such as the EUSSPs, have not been compared to global ones in heat risk assessments, and most of the existing studies focus only on a specific period in the future without comparing temporal trends.

We project heat-related risks for Finland by combining all SSPs with three RCPs. Despite its northerly location, there has been a significant level of heat-related mortality and morbidity in Finland (Ruuhela et al. 2018, 2021; Kollanus et al. 2019; Sohail et al. 2020), and the ageing population faces increased vulnerability and heat-related risks (Carter et al. 2016). We develop a methodology to project future vulnerability and risk at the postal code area scale (mean area $112 \mathrm{~km}^{2}$ ). In contrast to previous empirical heat-related mortality studies (Chen et al. 2017; Botzen et al. 2020; Marsha et al. 2016; Mora et al. 2017), we take an indicator-based approach to future vulnerability and risk. We compare the global SSPs to EUSSPs, which have different spatial and temporal scales. We ask the following questions: (1) what kind of differences are there in heat vulnerability projections with different scenarios, scales, and timespans, and (2) how the use of socio-economic scenarios influences heat risk projections up to 2100 ?

\section{Materials and methods}

\subsection{Scenario sets}

We chose the three available RCPs for Finland: RCP2.6, RCP4.5, and RCP8.5 (Finnish Meteorological Institute 2018). The first two are intermediate scenarios, with the difference that RCP2.6 relies partly on negative emissions, and the last scenario is an energy-intensive worst-case scenario (Van Vuuren et al. 2011). We compared two sets of socio-economic scenarios: five SSPs, the narratives of which have been described on a global scale, and three extended SSPs, the narratives of which have been specified for the European Union (hereafter EUSSPs). SSP1 is a sustainable scenario focused on the well-being of the population and the preservation of common goods. SSP2 represents "middle of the road", consistent with typical patterns of changes during the past century. SSP3 is characterized by regional rivalries and conflicts, with difficult global cooperation. SSP4 is the scenario of inequality, with a fall in social cohesion and an increasingly powerful elite. SSP5 is the road of fossil fuel development but allowing massive investments in human capital (O’Neill et al. 2017). EUSSPs narratives follow these outlines: in EUSSP1, Europe's ambitious environmental measures enable a reduction in inequalities and instabilities; in EUSSP3, new crises weaken the EU, provoking nationalism, retrenchment, and inequality until the possible breakdown of the EU; and in EUSSP4, the concentration of power in the hands of the elites greatly increases inequality but allows the EU to assert itself on the world stage and to overcome economic crises (Kok et al. 2018). Kok et al. (2018) also provide a narrative for the EUSSP5, consistent with SSP5; however, we excluded this scenario from our analysis, as there were no quantitative projections available for this scenario for the chosen vulnerability indicators.

\subsection{Overview of methods}

We constructed projections of the three risk components (hazard, exposure, and vulnerability) based on scenario data (Fig. 1, Table 1). First, we projected three sets of vulnerability for 2050: 


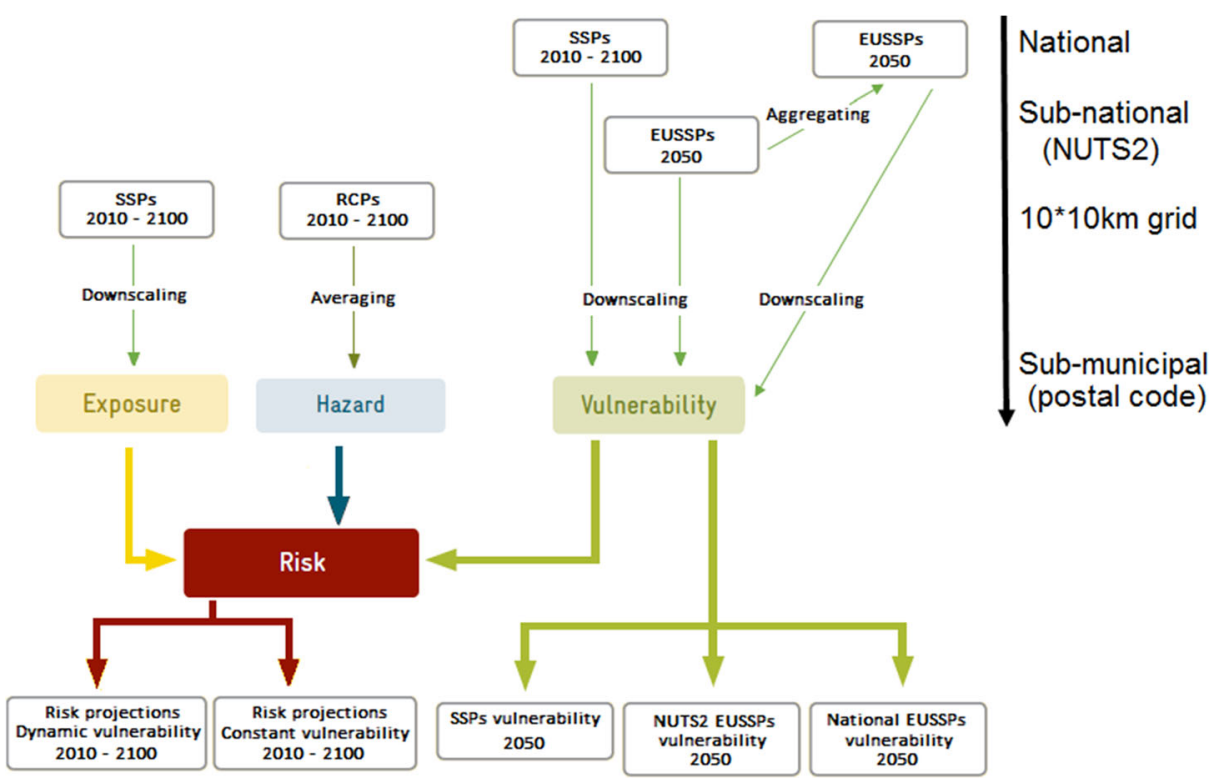

Fig. 1 Methodological framework of the study. In downscaling, we used the current values available for postal code areas. In risk index, vulnerability projections were based on SSPs only

one with five global SSP scenarios; the second with three EUSSP scenarios with detailed data at the sub-national scale $\left(\mathrm{NUTS}^{1}\right.$ ); and the last with EUSSP scenarios but with aggregated data at the national scale. Next, we projected two sets of risk projections between 2010 and 2100: one considering constant vulnerability (2010 values), the other considering dynamic vulnerability using the global SSP scenarios. In the risk projections, we gave equal weights when summing the different risk components, which is a common procedure in climate risk index studies (e.g. Binita et al. 2021; Shukla et al. 2021). We downscaled all projections to the postal code area scale based on current distributions to build detailed maps and compare spatial patterns. Following Rohat et al. (2019a), we ranked the resulting risk and vulnerability values based on deciles: very high $\left(9^{\text {th }}-10^{\text {th }}\right.$ deciles $)$, high $\left(7^{\text {th }} \_8^{\text {th }}\right.$ deciles $)$, moderate $\left(5^{\text {th }} \_6^{\text {th }}\right.$ deciles $)$, low ( $3^{\text {rd } \_4^{\text {th }}}$ deciles $)$, and very low ( $1^{\text {st }-2^{\text {nd }}}$ deciles $)$. To allow comparison with the current situation, indices based on the most recent data available (later referred to as "current values") (Table 1) were calculated. We conducted the analyses in R (R Core Team 2020) with packages ncdf4 (Pierce 2019), plyr (Wickham 2011), car (Fox and Weisberg 2019), and matrixStats (Bengtsson 2020). The maps were generated in QGIS 3.15.

\subsection{Choosing and weighting vulnerability determinants}

We derived vulnerability determinants from a local heat vulnerability study in the Helsinki Capital Region (Räsänen et al. 2019). The determinants were childhood, elderly, gender, economic status, education level, immigration, and weak social networks, each of which is specified with a quantitative indicator (Table 1). Justification for each determinant and indicator is provided in Räsänen et al. (2019); however, for two determinants, we used

\footnotetext{
${ }^{1}$ NUTS (European Nomenclature of territorial units for statistics) areas are used by the European Union for statistical and regional policy purposes; in Finland, there are 5 NUTS2 areas with an average size of $63,000 \mathrm{~km}^{2}$.
} 


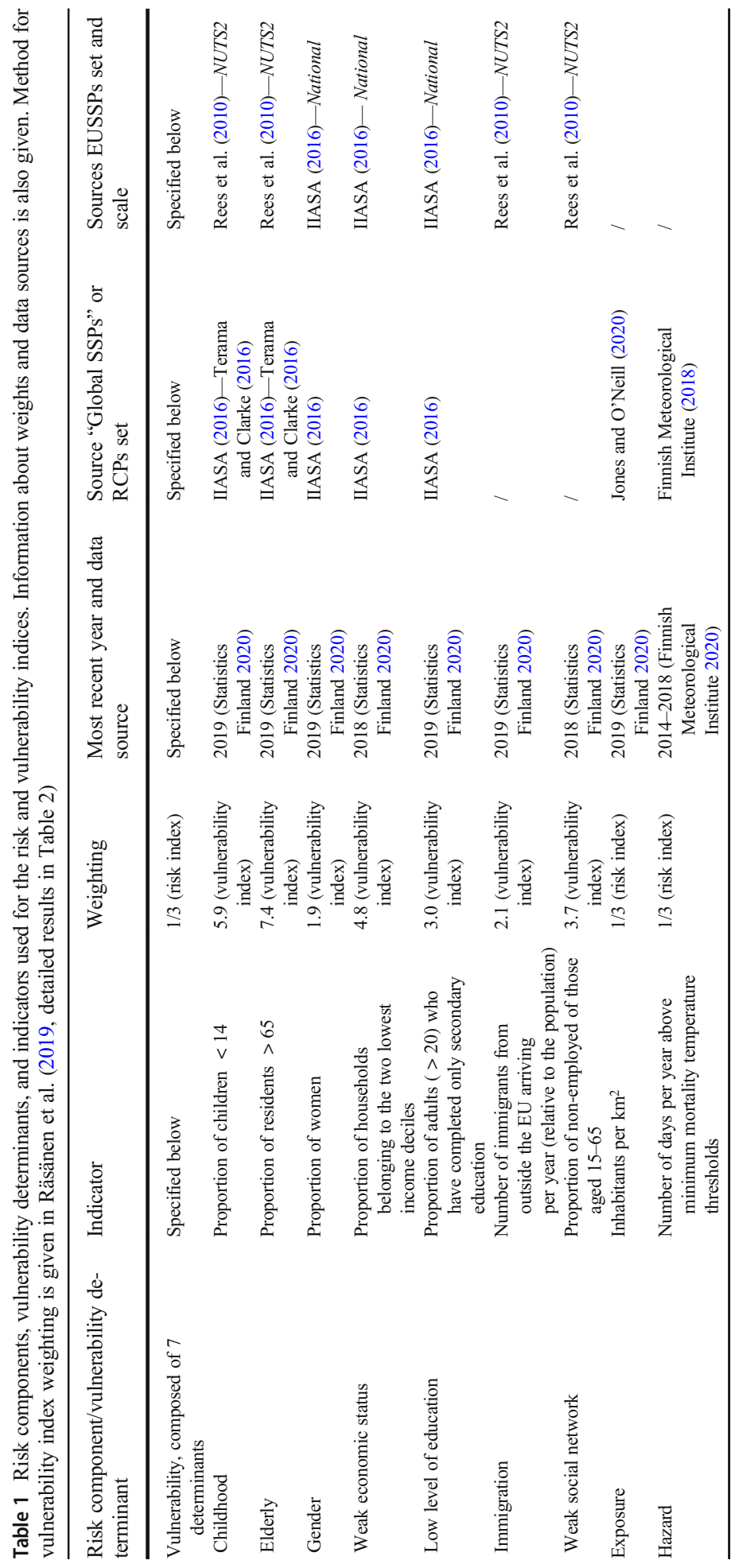


different indicators other than Räsänen et al. (2019). For immigration, we used immigration only from outside the EU. This is justified by a significant difference in integration and language barriers between immigrants from the EU (mainly Sweden, 2764, and Estonia, 2003, in 2019), and those from the rest of the world (mainly Russia, 2348), who may also suffer from social exclusion (Mannila and Reuter 2009). For weak social networks, instead of unemployment, we considered the non-employed in their entirety. This is justified by the social isolation of other non-employed than unemployed (Algren et al. 2020).

We accounted for the relative importance of each determinant by implementing weighting results from the previous Delphi assessment in the Helsinki Capital Region, which was conducted involving nine experts from different sectors of society (Räsänen et al. 2019, Table 1). To ensure that the indicators were not redundant, we assessed multicollinearities with the variance inflation factor (VIF) analysis using current values. All VIF values were < 3.5, below the often-used threshold of 4 (O'Brien 2007), and were thus kept in the analysis.

\subsection{Zoning vulnerability determinants}

Spatial resolution should be chosen to correspond to the scale at which the disparities in vulnerability are best observed (De Sherbinin et al. 2019). In our initial comparison between the municipal scale $\left(\mathrm{n}=310\right.$, average size $\left.1093 \mathrm{~km}^{2}\right)$ and the finer postal code area scale $(\mathrm{n}=$ 3026, average size $112 \mathrm{~km}^{2}$ ), it became evident that only the latter allowed for the correct illustration of the notable intra-municipal variations. Nevertheless, for immigration, we used data at municipal scale due to unavailability of finer scale data. Due to confidentiality matters, data from areas with less than 30 people were not available; thus, we removed 277 areas.

\subsection{Projecting and downscaling vulnerability indicators}

Vulnerability projection data were derived from the national-scale SSP projections (IIASA 2016), the downscaling of the age structure at the NUTS2 scale of these same projections by Terama and Clarke (2016), described in Terama et al. (2019), and NUTS2-scale data by Rees et al. (2010) (Table 1).

We compared four ways to account for future vulnerability: a constant vulnerability based on the SSP baseline in 2010, and three projections of vulnerability. The first vulnerability projection option is based on the projections of global SSPs at the scale of Finland only (not all indicators are available (Table 1)). The second option is based on the scenario matching logic described in Rohat et al. (2018), who projected three EUSSPs using data from European demographic scenarios (Rees et al. 2010) (Table 1). To enable additional spatial comparisons, in the third projection option, the NUTS2-scale projections of the EUSSPs were aggregated to the national scale (later referred to as "EUSSPs based on national values"). The baseline year for the SSP projections is 2010 while EUSSP projections exist only for the year 2050 (no baseline). Despite the inclusion of only 5 determinants (childhood, elderly, gender, economic status, and education), the global SSP dataset remains robust as these are among the main heatrelated vulnerability determinants (Reckien et al. 2017), and elderly, childhood, and economic status had the highest weights in the used Delphi evaluation (Table 1).

To ensure a fine-scale spatial differentiation, we performed a downscaling from the national or NUTS2 scale to the postal code area scale assuming a homogeneous evolution, as has been done before (e.g. Marsha et al. 2016). We used the methodology from Gao (2017): we aggregated the current distribution of individuals belonging to a given indicator at the scale 
of the available projection (national or NUTS2); then, we divided each postal code area by the aggregated values to obtain the proportions they represent. Finally, the future projections were distributed according to these proportions. We used postal code-scale data from the current values due to the unavailability of 2010 data (baseline of SSP projections). For education, immigration, and economic status projections, additional assumptions had to be applied, due to the lack of data of these determinants in the SSPs or inconsistencies between the data sources. As the education levels in the SSPs and Finnish statistics were not compatible, we assumed that the change in the number of persons with only basic education (Finnish statistics) would be proportional to the change in the number of persons with less than tertiary education (SSP projection). Regarding immigration, we estimated that the distribution of non-EU immigrants at the municipal scale is alike to the distribution of immigrants from all origins. Finally, we conducted a regression analysis between current regional GDP/capita and the current proportion of low-income households (i.e. weak economic status) ( $\mathrm{R}^{2}$ 0.74; Figs. S1-S2), and then projected the weak economic status with the help of the GDP/capita SSP projections. The current GDP per capita and 2005 baseline data were obtained from Eurostats at NUTS2 (in Finland 5 areas) and NUTS3 (in Finland 19 areas) scales.

To increase comparability of the different indicators, we normalized the set of indicator projections by z-score method:

$$
Z_{i, t}=\frac{X_{i, t}-\bar{m}}{\sigma}
$$

where $\mathrm{X}_{i, t}$ is the value of a particular indicator for the $i^{\text {th }}$ postal code area in year $t$ and $\bar{m}$ and $\sigma$ are the average and standard deviation over all areas for the entire projected period (including the current values). The value of each indicator is thus centred on $Z=0$ and the standard deviation is 1 . The choice of the normalization method was based on its ability to be less disturbed by the extreme values than a min-max normalization and its better representativeness of the data (Baeck et al. 2011). After normalizing each indicator, we multiplied each indicator by its weight (Table 1), summed the weighted indicators, and then normalized the vulnerability index.

\subsection{Hazard indicators}

According to the 1981-2010 weather data by the Finnish Meteorological Institute, mean summer (June-August) temperature was $16.2{ }^{\circ} \mathrm{C}$ in Helsinki, southern Finland, and $12.6{ }^{\circ} \mathrm{C}$ in Sodankylä, northern Finland, while the annual average of days with $>19.9{ }^{\circ} \mathrm{C}$ mean temperature was 12.0 and 2.9 in Helsinki and Sodankylä, respectively. Based on the median of 28 climate models (CMIP5), mean summer temperatures are projected to be 1.5, 2.5, and 4.6 ${ }^{\circ} \mathrm{C}$ higher in 2070-2099 than in 1981-2010 in the RCP2.6, RCP4.5, and RCP8.5, respectively (Ruosteenoja et al. 2016).

We obtained mean temperature daily gridded time series under the three RCPs from the Finnish Meteorological Institute (2018) (Table 1). These projections are based on the ensemble mean of 13 downscaled CMIP5 global circulation models at the $10 \times 10 \mathrm{~km}$ scale, using the delta change method (Räisänen and Räty 2012) and a 1981-2010 baseline (Aalto et al. 2016).

Following the approach from Estoque et al. (2020), we used the minimum mortality temperature (MMT) threshold for the hazard indicator. Although the threshold approach is developed for mortality, we decided to use it for the heat-related health risks in general due to 
the better availability of data related to mortality compared to morbidity. To derive the temperature values, we relied on the biometeorological study in the Hospital District of Helsinki and Uusimaa, which related relative mortality (i.e. percentage deviation of mortality from expected mortality) to spatially averaged temperature (Ruuhela et al. 2017). We consider the use of the heat-mortality relationship calculated in Helsinki reliable for the whole country because Ruuhela et al. (2018) could not find a statistically significant difference between the Finnish regions in the relationships.

We followed the recommendation by Huang et al. (2011) to use not only a temperature-mortality relationship to define the heat threshold, but also the associated slope. Hence, we used not only the MMT threshold but also three other thresholds available in the study by Ruuhela et al. (2017), weighted by their influence on the increase in relative mortality over the past two decades: $16.7^{\circ} \mathrm{C}$, $18.6^{\circ} \mathrm{C}, 19.9^{\circ} \mathrm{C}$, and $21.4^{\circ} \mathrm{C}$ mean daily temperature, for increases in daily relative mortality of $1.1 \%, 2.6 \%, 6.1 \%$, and $10.7 \%$, respectively. In this way, hot and extremely hot days are differentiated since their impact and risk pattern can be significantly different (Zhang et al. 2019).

We calculated the number of days per year in each of these four intervals averaged over 5 years based on the climate projections for three RCPs at the $10 \times 10 \mathrm{~km}$ scale from 2010 to 2100 and weighted them. Similarly, we calculated the estimate of the current hazard using data for 2014-2018. We obtained the values for each postal area by averaging the values of the cells covering a specific postal code area and normalized with the z-score method to allow aggregation of hazard projections into our risk index.

\subsection{Exposure}

The exposure indicator was the population density (inhabitants per $\mathrm{km}^{2}$ ). We derived population projection data from a $1 / 8^{\circ}$ downscaling of national population and urbanization projections for the five SSPs (Jones and O’Neill 2020) (Table 1). These projections use a gravity-based approach to distribute the national population projections according to the attractiveness of each region. However, the scale is not sufficient to embrace the profound disparities in density that exist in urban areas. Therefore, we downscaled the projections to the postal code area scale following Gao (2017), as we did for vulnerability indicators. We normalized the projections from 2010 to 2100 with the z-score method.

\section{Results}

\subsection{Heat-related vulnerability projections}

Both the SSP and the EUSSP vulnerability projections for 2050 show a decrease in vulnerability in all scenarios compared to the current situation (Fig. 2). However, there are differences between the scenarios. The SSP5 and SSP1 had the lowest median values for vulnerability ( -0.106 and -0.099 , respectively), while the SSP3 and SSP2 the highest vulnerability (0.022 and -0.009 , respectively) (Fig. 2a). The SSP3 and SSP4 were the only two scenarios with an increase in regional variability of vulnerability (larger interquartile range), whereas the SSP5 reduced it significantly (Fig. 2a). In the EUSSP projections, the EUSSP1 stands out for its low vulnerability (median value of -0.353 ), followed by the EUSSP4 (-0.106) and the EUSSP3 (-0.08) [Fig. 2-b], which is the EUSSP scenario that reduces regional disparities the least compared to the current situation. 

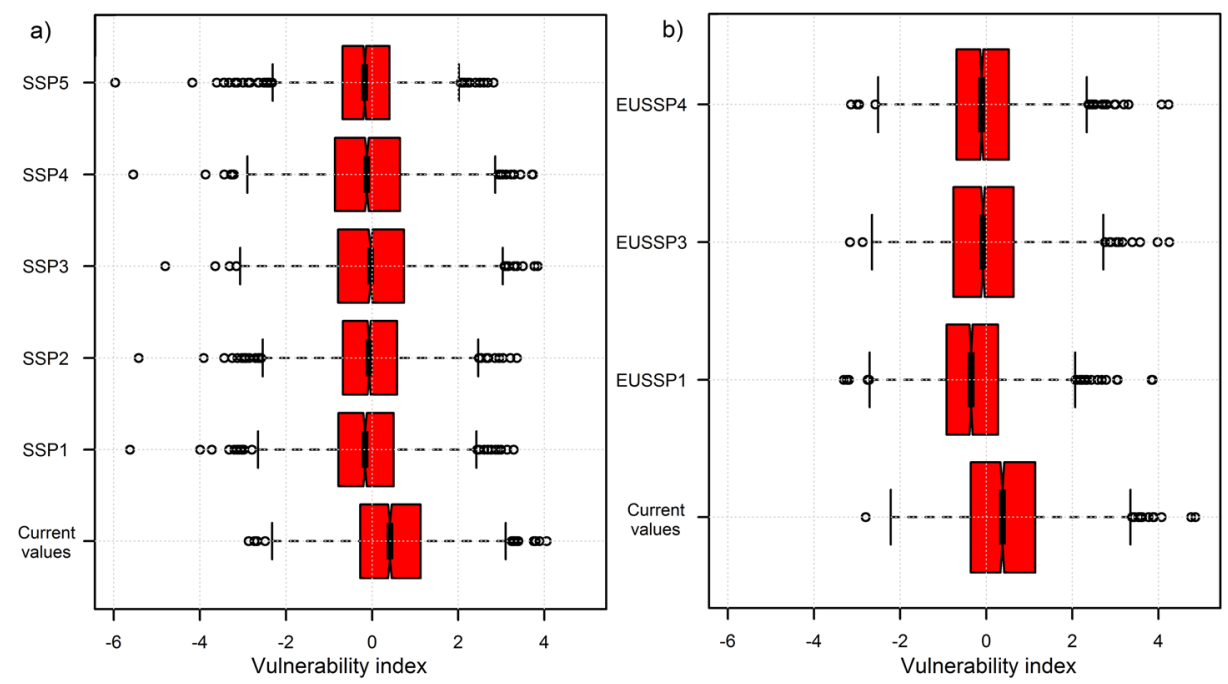

Fig. 2 Boxplots of variability in projected vulnerability in 2050 between all postal code areas, according to (a) SSPs and (b) EUSSPs. Current values are based on the most recent data available (2018-2019). The thick line is the median and the boxes extend from the 1st to the 3rd quartiles, the whiskers come out up to 1.5 times the interquartile range, and the dots are the extreme values (outliers)

These overall reductions and national-scale comparisons are confirmed by the vulnerability maps (Fig. 3). The contrast between the high-vulnerability areas (mostly rural) and the lowvulnerability areas (cities and urban peripheries) is striking in the SSP3 and SSP4 scenarios, as well as to some extent in the EUSSP3. The low disparities are particularly evident in the SSP5, in which some areas that are not very vulnerable today will be slightly more vulnerable in 2050. These notable differences between the socio-economic scenarios can be explained by the changes in different indicators (Fig. S3). Disparities are reduced in SSP5 through its high proportion of children and a reduction in low-income households. Conversely, inequalities increase in the SSP3 and SSP4, due to a stagnation or even a slight increase in the proportion of people with a low level of education. For the European scenarios, the same phenomenon applies for the EUSSP3 and EUSSP4. The inclusion of two additional indicators, immigration and non-employment, does not affect the trends identified. However, these trends in the scenarios up to 2050 change towards the end of the century.

In the vulnerability projections between 2010 and 2100 for the global SSPs (Fig. 4a), the SSP4 is the one with the lowest median until 2040 before it becomes the scenario that depicts the greatest vulnerability from the 2070s onwards. Similarly, the SSP5 shows the lowest vulnerability from 2050 onwards but the highest in 2030 .

When comparing the EUSSP projections based on the NUTS2 or national scale, the differences in spatial patterns are minor in 2050 (Fig. 3b, c). Between 72 and $74 \%$ of postal code areas belong to the same deciles in both maps. However, a slight north-south gradient can be seen on maps at NUTS2 scale, with the south being less vulnerable (Fig. 3d).

\subsection{Heat-related risk projections}

The current risk index for the different postal code areas, based on the 2014-2019 data (Table 1), shows that the areas least at risk are concentrated in the suburbs of the main cities, 
in the north of the country, and in the south-western archipelago. The areas with the highest risk are the centres of major cities, in particular the capital Helsinki in southern Finland, and some rural areas far from any agglomeration, mainly south-eastern Finland (Fig. 5a, b). This pattern remains very similar, regardless of the number of indicators included.

When only the hazard is projected, RCP8.5 and RCP4.5 scenarios show an increase in the amount of heat, mainly in the south-eastern Finland and along the coastline (Fig. S4). The use of exposure projections does not influence the median risk much, but rather the extreme values (i.e. highly populated postal code areas) (Fig. S5).
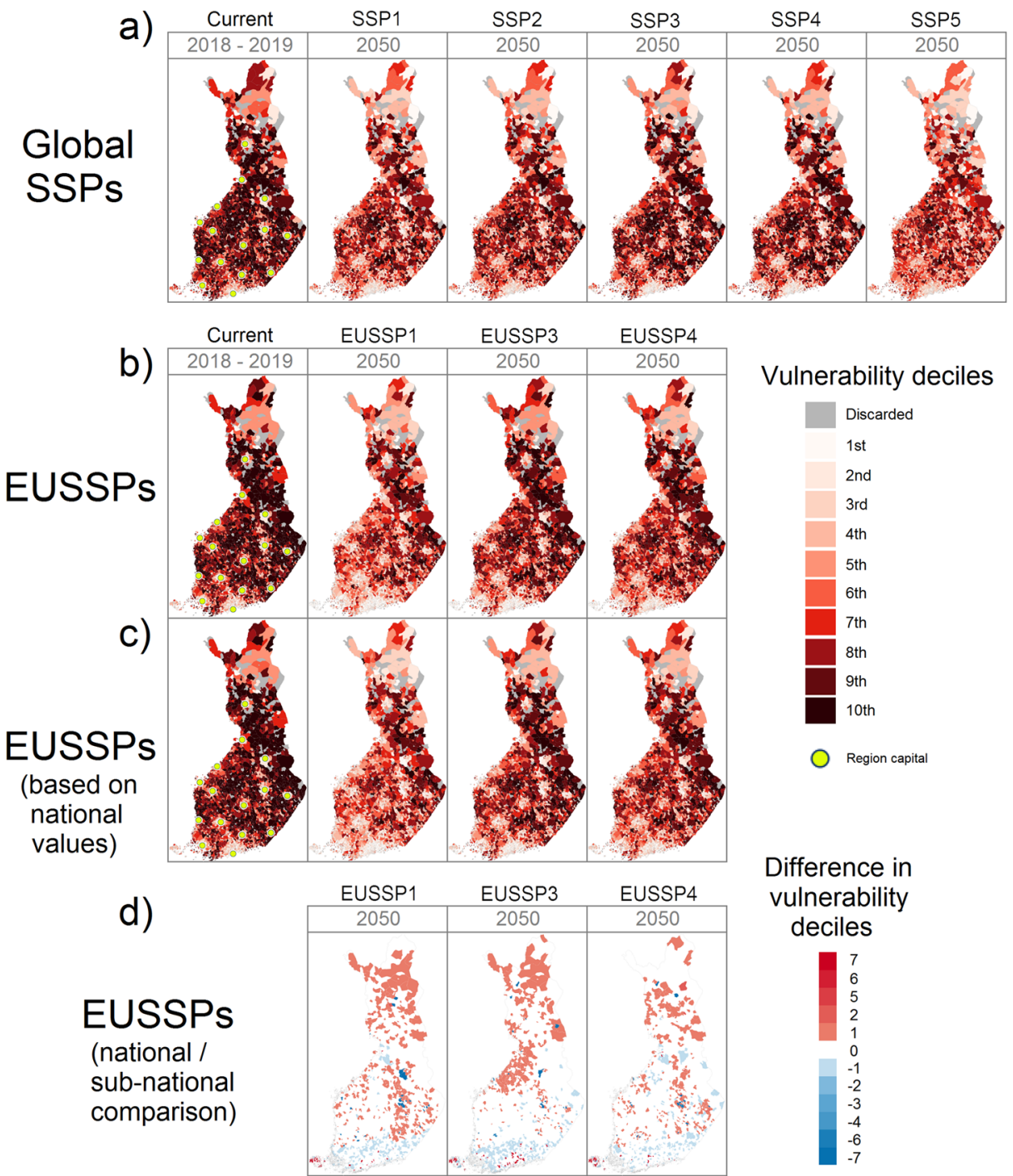

\section{Vulnerability deciles}
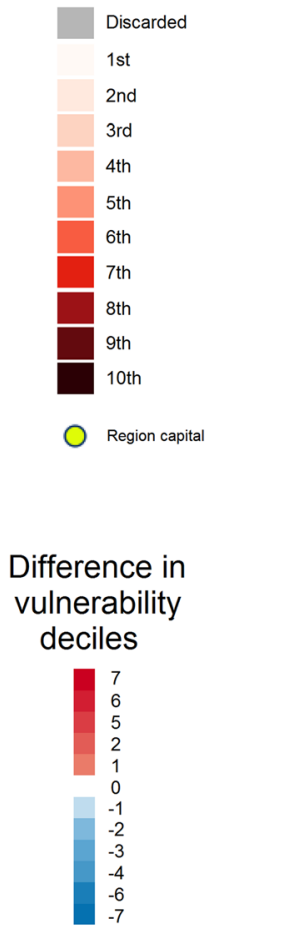

Fig. 3 Vulnerability maps at the postal code scale for (a) global SSPs; (b) EUSSPs; (c) EUSSPs based on national values; and (d) difference in deciles between EUSSPs projections based on NUTS2 scale and national scale (a positive difference means higher vulnerability in the sub-national projection). Discarded areas are due to no socio-economic data available 

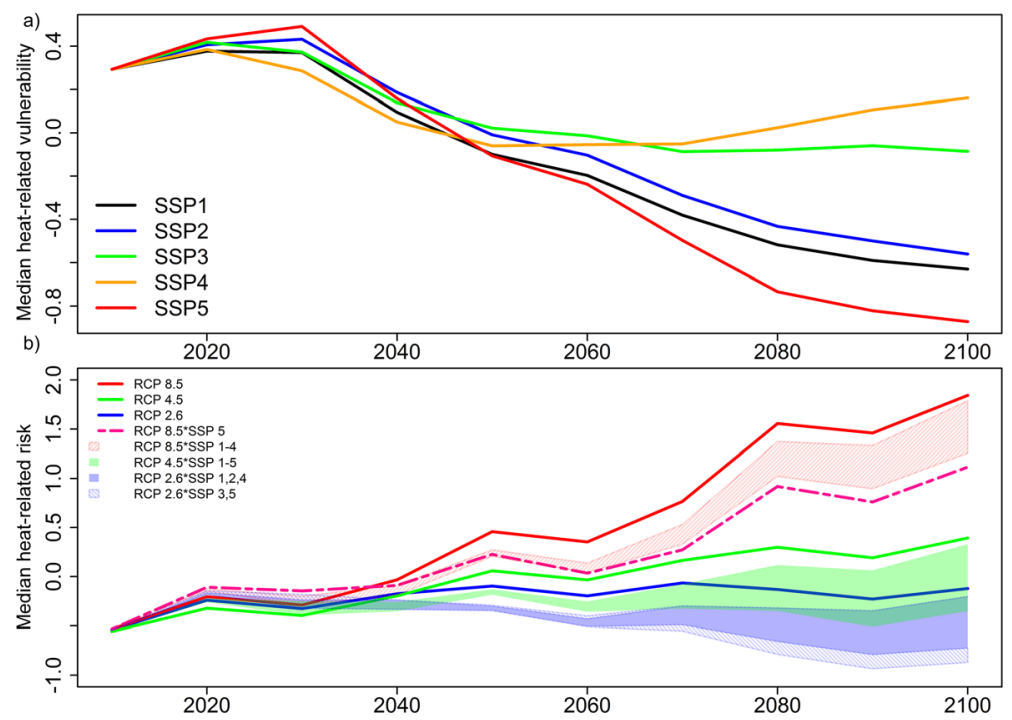

Fig. 4 (a) Vulnerability median value evolution from 2010 to 2100 for the five global SSPs; (b) median risk projections from 2010 to 2100 based on temperature-based hazard from 13 CMIP5 GCMs, exposure and social vulnerability indicators: RCPs - constant vulnerability (2010) in thick line and combinations of RCPs*SSPs in light colored stripe. According to Riahi et al. (2017), RCP8.5 is compatible only with SSP5 (pink dashed line), the other combinations have been calculated purely as an indication (red hatched color band). Similarly, the combinations RCP2.6*SSP3 and RCP2.6*SSP5 are implausible (blue hatched color band)

Projecting the median heat-related risk over time, using either the constant vulnerability (based on the 2010 baseline) or dynamic vulnerability, shows that the latter has a strong influence (Fig. 4b). Until 2030, all socio-economic scenarios induce a higher increase in heat risk than climate alone. Between 2030 and 2050, this trend is reversed and the reduction in the range of possibilities is observed, with socio-economic factors partially (or even totally in the case of RCP2.6) compensating for the temperature increase. At the same time, the median risk in the RCP2.6 scenarios moves below that in the RCP4.5 scenarios. In the second half of the century, the climate stabilizes for RCP2.6, increases slowly for RCP4.5, and rises sharply for RCP8.5 until 2100. The differences between the SSPs also increase, shown as a widening of the SSP*RCP bands in Fig. 4b. From 2070 onwards, the SSP4 aggravates the risk, catching up very quickly with the constant vulnerability projection. Conversely, the SSP5 (and SSP1 and SSP2 to a lesser extent) implies an increasingly reduced risk. Thus, if the climate follows the intermediate scenarios, SSP1, SSP2, and SSP5 make it possible to maintain the risk at the level of the one in 2020 or below. This difference between the socioeconomic scenarios may even lead to a situation in which the SSP5*RCP4.5 combination has lower median risk than SSP4*RCP2.6 from 2070 onwards.

These results are also clearly visible in the spatial projections, where the divergences are striking from the second half of the century onwards (Fig. 5c). The maps where vulnerability remains constant in the projections show a homogeneous increase in risk throughout the country (except Lapland covering the northern one-third of the country), with a very marked increase in the southeast and south-western coast. By contrast, the socio-economic scenarios are much more nuanced. For the SSP1, SSP2, and SSP5 scenarios, the risk is mitigated and concentrated more in the very dense city centres and in the rural areas in south-eastern Finland. 


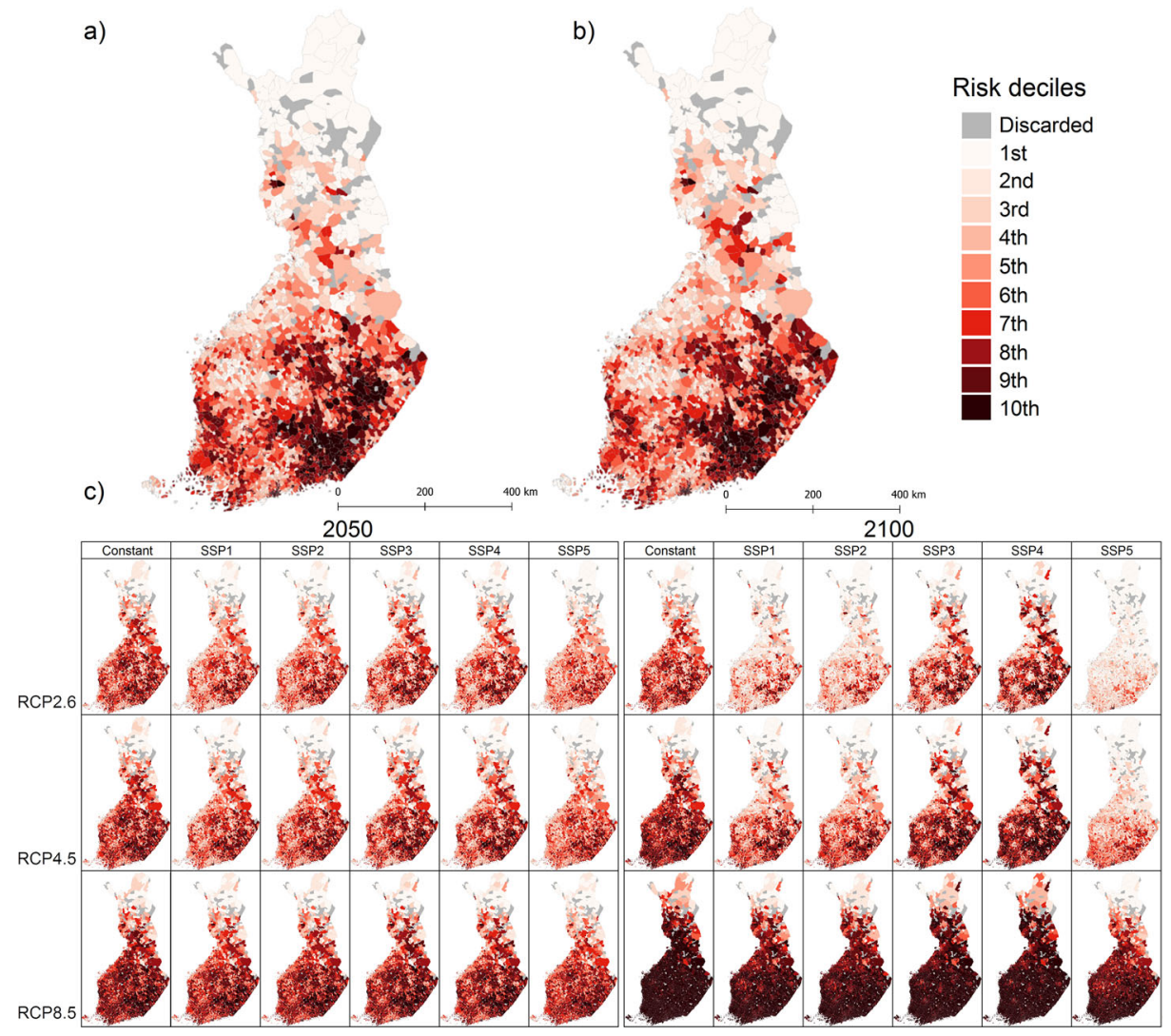

Fig. 5 Maps of current heat-related risks in Finland with vulnerability indicators: (a) age, gender, income and education; (b) age, gender, income, education, immigration, and non-employment. (c) Risk maps using RCPs - constant vulnerability projections (2010 values) and global SSPs-RCPs projections in 2050 and 2100 at the postal code scale. Discarded areas are due to no socio-economic data available

The SSP3 and SSP4, for their part, show a contrast between urban and rural areas, the latter being more at risk than in the constant vulnerability projection.

\section{Discussion}

The differences in vulnerability projections between the global SSPs and EUSSPs for 2050 were small, despite the inclusion of two additional indicators in the EUSSPs. The comparison between EUSSP projections based on either national or sub-national (NUTS2) scale also showed a strong similarity, although a north-south gradient appeared. Additionally, the comparison highlighted the limitation of the projections for a single time point (i.e. 2050), since the trends evolve strongly throughout the twenty-first century.

We found clear differences when comparing the risk projections where vulnerability remained constant with those where vulnerability was considered dynamic. These differences were apparent both in spatial patterns and in temporal trends. Urban-rural disparities were more pronounced, depending on the scenario, and differences between the scenarios were 
projected to increase by the end of the century. Additionally, divergent combinations of RCPs and SSPs led to very different levels of risk.

\subsection{Consistency with the narratives and between the datasets}

While our results show common trends in all socio-economic scenarios with a reduction of vulnerability in 2050 from the present, significant differences can emerge in the future depending on the path followed. Two global SSPs stand out: the SSP4 shows the highest risk and the SSP5 the lowest risk in 2100. The SSP4 is the scenario of inequality, particularly in terms of income and education, which confirms our findings, especially concerning disparities. The SSP5 is the scenario of fossil fuel development, allowing massive investments in health, education, and sustained demographic/economic growth but based on a very carbon energyintensive lifestyle (O'Neill et al. 2017). As a result, the combination between SSP5 and RCP2.6 is implausible (Riahi et al. 2017; Rohat et al. 2019a), and the combination of SSP1 and RCP2.6 has probably the lowest risk, since SSP1 reduces vulnerability the most after SSP5. This scenario, despite a slowdown in economic growth, is more focused on social and environmental sustainability (O'Neill et al. 2017).

When considering the EUSSPs for 2050, the EUSSP1 depicts the least risk and the EUSSP3 the worst case possible, being slightly worse than EUSSP4 ${ }^{2}$. The descriptions of the EUSSP1 and EUSSP4 are consistent with the storyline of the global SSP1 and SSP4, and the EUSSP3 is characterized by nationalism, retrenchment (less immigration), and short-term utility maximization. In the long term, the pathway of EUSSP3 leads to a fall in trade and therefore a slowdown in the general economy of countries, which has repercussions on investment in education and health (Rohat et al. 2018; Kok et al. 2018). Our results appear to follow the scenario descriptions, even if the divergences between the EUSSP3 and EUSSP4 scenarios are not yet extremely clear in 2050. However, as with the projections of global SSPs, large differences should emerge during the second half of the century.

The use of two sets of SSPs, global and EU, indicates a strong similarity in heat-related risk, in both spatial patterns and trends (Fig. 2, Fig. 3). To internally validate our study, we tested the sensitivity of the projections to the weightings and then to the normalization method (Fig. S6), and these trends were maintained during these tests. We also tested using the age structure of the SSP dataset in the EUSSP dataset which also did not affect the trends. This concordance between the two sets of scenarios, the narratives of which differ in scale, reinforces the reliability of our results. However, they may also show that the extension of the global scenarios to include local specificities does not deeply affect the results of the projections regarding heat-related risk. Obviously, this observation should be taken with a pinch of salt. Firstly, 3 out of 7 indicators in EUSSPs come from global SSPs. Secondly, the divergences between scenarios appear more clearly in the second half of the century, whereas the EUSSPs are projected only for 2050. Moreover, the population age structure is not the same in the two sets of projections: the proportion of elderly people is expected to increase in the SSPs but stagnate in the EUSSPs (Fig. S3).

\subsection{Choosing and weighting indicators}

Our results for 2050 can be compared with those calculated for the EU at the $0.1^{\circ}$ scale (Rohat et al. 2019a). The current situation is similar in both studies, with the periphery of Greater

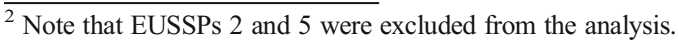


Helsinki at very low risk and a moderate risk in the southeast of the country. The differences between the socio-economic scenarios are also confirmed: the EUSSP1 scenario shows by far the least risk with a constant climate, the other two being hardly different from each other, although the EUSSP3 depicts slightly more risk. However, the spatial distribution of risk differs significantly between our and Rohat et al.'s (2019a) results. In Rohat et al. (2019a), the southwest seems to be as affected as the southeast, while the rural areas in the centre of the country are not. This difference could be explained by the choice of vulnerability determinants and indicators. Rohat et al. (2019a) included artificial surfaces and overweight but excluded immigration and gender, and used a different indicator for social isolation, i.e. elderly living alone instead of non-employment. According to Rohat et al. (2019a), the proportion of elderly living alone will increase in the low vulnerability scenarios (SSPs 1 and 5) and slightly decrease in high vulnerability scenarios (SSPs 3 and 4), while overweight will increase in particular in high vulnerability scenarios.

Despite some local spatial differences (Fig. 3), our results are consistent in 2050, whether five or seven indicators are included in the vulnerability index. Nevertheless, the discussion above shows the importance in the choice of indicators (Reckien 2018; Estoque et al. 2020). To improve the projection accuracy, health status should be included as it is identified as an important determinant of vulnerability (Reckien et al. 2017; Räsänen et al. 2019). For this, the projections of health indicators need to be developed, as was done by Rohat (2018), based on health-extended SSPs (Sellers and Ebi 2017). In addition to the choice of determinants, the weighting of them can have a major impact (Reckien 2018). We used a weighting scheme developed for the Helsinki Capital Region (Räsänen et al. 2019), which should be accurate also for all Finland, but a more targeted weighting could have slightly changed the results. Overall, vulnerability indices are simplifications of vulnerability, which is a complex and immeasurable phenomenon (Hinkel 2011); therefore, the index results need to be evaluated critically and linked to the analysis of mechanisms and drivers that increase vulnerability.

Based on our results, the decline in vulnerability is even greater in some combinations of climate and socio-economic scenarios than the rise in temperature, reducing long-term risks. However, the result depends on how the different risk components are weighted, and there are uncertainties in the future projections (Vanos et al. 2020). Our findings are in line with the empirical results showing a decline in the heat-related mortality in the Czech Republic, despite climate change (Kyselý and Plavcová 2011) and by modelling results indicating that future excess heat-related mortalities in Greater Houston are mostly driven by changes in exposure and vulnerability instead of changes in climate (Rohat et al. 2019b). Our results are contrasted by Carter et al. (2016) who project highest increases in mortality for southern Finland with higher temperature and urban areas with high population. Nevertheless, Carter et al. (2016) do not take socio-economic characteristics into account and conduct projections only up to 2040.

\subsection{Further development of scenarios}

The downscaling of climate projections at the $10-\mathrm{km}$ grid scale does not account for the urban heat island (UHI) effect, which is recognized as an important aggravating factor of heat-related risks (Klein Rosenthal et al. 2014). It has also been shown that the effect of UHI is evident in Finland (Miles and Esau 2020) and can be seen on the current visualization of the hazard (Fig. S4). Furthermore, it has been shown that heat-related mortality risk is higher in Helsinki than 
in the more sparsely populated surrounding areas (Ruuhela et al. 2021). The UHI could be captured by using urbanization and demographic projections in the SSPs to generate projections of UHI for different RCPs (Rohat et al. 2019b).

Populations are gradually acclimatizing to climate change (Huang et al. 2011); therefore, the hazard thresholds used in our study may not hold in the future. More specifically, the acclimatization should reduce the impact of climate on heat-related risks, which would aggravate the role of some vulnerability determinants. Methods for projecting future acclimatization have been compared, advising the use of MMT shift and slope reduction in the mortality/temperature relationship (Gosling et al. 2017). In the biometeorological study we used to define our temperature thresholds, the MMT has not significantly increased over the last 40 years, despite the increase in average temperature. However, mortality per additional degree has fallen significantly (Ruuhela et al. 2017). Nevertheless, future studies could analyse acclimatization in Finland and in other regions over a longer time series to allow a projection of empirical trends.

To refine the projections, qualitative and quantitative SSP scenarios could be developed at a more detailed scale than the EU, for instance national or city scale. Methods have been developed to achieve this, allowing the extension of the SSPs to sub-national scales (Absar and Preston 2015; Rohat et al. 2019b), for example for the Baltic Sea region, with the production of four narratives focusing on fisheries (Zandersen et al. 2016). Regarding Finland, narratives have been adapted from global socio-economic scenarios and certain variables, such as GDP or population, have been projected, either with trends or with quantified data (Kaivooja et al. 2004; Carter et al. 2004, 2005). However, these scenarios are based on the former SRES scenarios, which combine socio-economic and climate projections, instead of SSPs.

As discussed above, the use of EUSSPs does not appear to significantly alter heat risk projections compared to the global scenarios. In addition, our results show that the differences between socio-economic projections using quantitative data at the national or sub-national scale are small. However, Finland contains only 5 NUTS2 regions, whereas countries such as Germany or the UK contain 38 and 40, respectively. This leads directly to a limited difference between national and sub-national values, although a north-south gradient was observed. Further studies should be carried out to measure the actual improvement at more local scales in other countries.

\section{Conclusion}

We show how climate and socio-economic changes will impact heat-related risk in Finland in the coming decades. By comparing different possible scenarios, we illustrate how projections of vulnerability in the future have a considerable impact on heat-related risks in the future. Future risk assessments should therefore include the combination of climatic and socioeconomic projections. As the risk trends evolve strongly in the latter half of the century, we also suggest that these assessments, including socio-economic projections, should be conducted for 2100. We did not find evidence for the need to develop finer scale projections or local socio-economic scenarios in heat risk projection because of small differences in vulnerability projections between the global SSPs, EUSSPs, and EUSSPs based on the national values for 2050. However, differences in population age structure between SSPs and EUSSPs and the north-south vulnerability gradient at the sub-national scale suggest that future studies should investigate this issue. The results, and in particular vulnerability and exposure projections, can 
help stakeholders disentangle how societal development is linked to future climate risks and how adaptation planning can be targeted not only to areas with high future hazard but also to areas with high vulnerability and exposure.

Supplementary Information The online version contains supplementary material available at https://doi.org/ 10.1007/s10584-021-03148-3.

Code availability Available from the corresponding author upon a reasonable request.

Author contribution AR had the original idea and planned the study together with AL and SJ. AL conducted the data analyses under supervision of SJ and AR. AL wrote the first draft of the manuscript, while SJ, AJ, and AR contributed to writing and editing.

Funding Open access funding provided by University of Helsinki including Helsinki University Central Hospital. This work received funding from the Academy of Finland (grant 329239).

Data Availability Available from the corresponding author upon a reasonable request.

\section{Declarations}

Conflict of interest The authors declare no competing interests.

Open Access This article is licensed under a Creative Commons Attribution 4.0 International License, which permits use, sharing, adaptation, distribution and reproduction in any medium or format, as long as you give appropriate credit to the original author(s) and the source, provide a link to the Creative Commons licence, and indicate if changes were made. The images or other third party material in this article are included in the article's Creative Commons licence, unless indicated otherwise in a credit line to the material. If material is not included in the article's Creative Commons licence and your intended use is not permitted by statutory regulation or exceeds the permitted use, you will need to obtain permission directly from the copyright holder. To view a copy of this licence, visit http://creativecommons.org/licenses/by/4.0/.

\section{References}

Aalto J, Pirinen P, Jylhä K (2016) New gridded daily climatology of Finland: permutation-based uncertainty estimates and temporal trends in climate. J Geophys Res Atmos 121:3807-3823. https://doi.org/10.1002/ $2015 \mathrm{jd} 024651$

Absar SM, Preston BL (2015) Extending the shared socioeconomic pathways for sub-national impacts, adaptation, and vulnerability studies. Glob Environ Change 33:83-96. https://doi.org/10.1016/j.gloenvcha.2015. 04.004

Adger WN, Brown I, Surminski S (2018) Advances in risk assessment for climate change adaptation policy. Philosophical Transactions of the Royal Society A: Mathematical, Physical and Engineering Sciences 376. https://doi.org/10.1098/rsta.2018.0106

Algren MH, Ekholm O, Nielsen L, Ersbøll AK, Bak CK, Andersen PT (2020) Social isolation, loneliness, socioeconomic status, and health-risk behaviour in deprived neighbourhoods in Denmark: a cross-sectional study. SSM-population health 10:100546. https://doi.org/10.1016/j.ssmph.2020.100546

Anderson GB, Oleson KW, Jones B, Peng RD (2016) Projected trends in high-mortality heatwaves under different scenarios of climate, population, and adaptation in 82 US communities. Clim Change 146:455470. https://doi.org/10.1007/s10584-016-1779-x

Baeck S, Choi S, Hong S, Kim D (2011) A study on comparison of normalization and weighting method for constructing index about flood. J Wetl Res 13:411-426. https://doi.org/10.17663/JWR2011.13.3.411 
Bengtsson H (2020). matrixStats: functions that apply to rows and columns of matrices (and to vectors). $\mathrm{R}$ package version 0.56.0. https://CRANR-project.org/package=matrixStats

Binita KC, Shepherd JM, King AW, Gaither CJ (2021) Multi-hazard climate risk projections for the United States. Nat Hazards 105:1963-1976. https://doi.org/10.1007/s11069-020-04385-y

Botzen WJW, Martinius ML, Bröde P, Folkerts MA, Ignjacevic P, Estrada F, Daanen HAM (2020) Economic valuation of climate change-induced mortality: age dependent cold and heat mortality in the Netherlands. Clim Change 162:545-562. https://doi.org/10.1007/s10584-020-02797-0

Carter TR, Fronzek S, Bärlund I (2004) FINSKEN: a framework for developing consistent global change scenarios for Finland in the 21st century. Boreal Environ Res 9:91-107

Carter TR, Jylhä K, Perrels A, Fronzek S, Kankaanpää S (2005). FINADAPT scenarios for the 21st century. Alternative futures for considering adaptation to climate change in Finland. FINADAPT Working Paper 2.

Carter TR, Fronzek S, Inkinen A, Lahtinen I, Lahtinen M, Mela H, Terama E (2016) Characterising vulnerability of the elderly to climate change in the nordic region. Reg Environ Change 16:43-58. https://doi.org/10.1007/ s10113-014-0688-7

Chen K, Horton RM, Bader DA, Lesk C, Jiang L, Jones B, Kinney PL (2017) Impact of climate change on heatrelated mortality in Jiangsu Province, China. Environ Pollut 224:317-325. https://doi.org/10.1016/j.envpol. 2017.02.011

Chen Q, Ding M, Yang X, Hu K, Qi J (2018) Spatially explicit assessment of heat health risk by using multisensor remote sensing images and socioeconomic data in Yangtze River Delta, China. Int J Health Geogr 17: 15. https://doi.org/10.1186/s12942-018-0135-y

De Sherbinin A, Bukvic A, Rohat G, Gall M, McCusker B, Preston B, Zhang S (2019) Climate vulnerability mapping: a systematic review and future prospects. Wiley Interdiscip Rev Clim Change 10:e600. https://doi. org/10.1002/wcc. 600

Dellink R, Chateau J, Lanzi E, Magné B (2017) Long-term economic growth projections in the shared socioeconomic pathways. Glob Environ Change 42:200-214. https://doi.org/10.1016/j.gloenvcha.2015.06. 004

Dilling L, Daly ME, Travis WR, Wilhelmi OV, Klein RA (2015) The dynamics of vulnerability: why adapting to climate variability will not always prepare us for climate change. Wiley Interdiscip Rev Clim Change 6:413425. https://doi.org/10.1002/wcc.341

Dosio A, Mentaschi L, Fischer EM, Wyser K (2018) Extreme heat waves under $1.5^{\circ} \mathrm{C}$ and $2{ }^{\circ} \mathrm{C}$ global warming. Environ Res Lett 13:054006. https://doi.org/10.1088/1748-9326/aab827

Elsawah S, Hamilton SH, Jakeman AJ, Rothman D, Schweizer V, Trutnevyte E, van Delden H (2020) Scenario processes for socio-environmental systems analysis of futures: a review of recent efforts and a salient research agenda for supporting decision making. Sci Total Environ 729:138393. https://doi.org/10.1016/j. scitotenv.2020.138393

Estoque RC, Ooba M, Seposo XT, Togawa T, Hijioka Y, Takahashi K, Nakamura S (2020) Heat health risk assessment in Philippine cities using remotely sensed data and social-ecological indicators. Nat Commun 11: 1-12. https://doi.org/10.1038/s41467-020-15218-8

Finnish Meteorological Institute (2018) Daily mean temperature predictions, 1981-2100. CSC - IT Center for Science Ltd. https://etsin.fairdata.fi/dataset/7f3d71c5-647e-4ddc-8ac3-dbb3a55dflda Accessed 26 Mai 2020.

Finnish Meteorological Institute (2020). Daily mean temperature, 10km, 1961-2020. NetCDF, CSC - IT Center for Science Ltd. https://etsin.fairdata.fi/dataset/e6fcda7b-a72a-453f-88ba-41acbe94fb8a Accessed 25 July 2020

Ford JD, Pearce T, McDowell G, Berrang-Ford L, Sayles JS, Belfer E (2018) Vulnerability and its discontents: the past, present, and future of climate change vulnerability research. Clim Change 15:189-203. https://oi. org/10.1007/s10584-018-2304-1

Fox J, Weisberg S (2019) An $\{R\}$ companion to applied regression, Third edn. Sage, Thousand Oaks CA https:// socialsciences.mcmaster.ca/jfox/Books/Companion/

Gao J (2017) Downscaling global spatial population projections from 1/8-degree to 1-km grid cells. In: Technical Notes NCAR, National Center for Atmospheric Researcher. Boulder, CO., USA. https://doi.org/10.5065/ D60Z721H

Gosling SN, Hondula DM, Bunker A, Ibarreta D, Liu J, Zhang X, Sauerborn R (2017) Adaptation to climate change: a comparative analysis of modeling methods for heat-related mortality. Environ Health Perspect 125:087008. https://doi.org/10.1289/ehp634

Hinkel J (2011) "Indicators of vulnerability and adaptive capacity": towards a clarification of the science-policy interface. Glob Environ Change 21:198-208. https://doi.org/10.1016/j.gloenvcha.2010.08.002

Huang C, Barnett A, Wang X, Vaneckova P, FitzGerald G, Tong S (2011) Projecting heat-related mortality under climate change scenarios: a systematic review. Environ Health Perspect 119:1681-1960. https://oi. org/10.1289/ehp.1103456 
IIASA (2016). SSP database (shared socioeconomic pathways) - version 1.1. International Institute for Applied Systems Analysis. https://tntcat.iiasa.ac.at/SspDb/dsd?Action=htmlpagepage=about Accessed 09 July 2020

IPCC (2014). Annex II: Glossary. In Climate Change 2014: Synthesis Report. Contribution of Working Groups I, II and III to the Fifth Assessment Report of the Intergovernmental Panel on Climate Change [Core Writing Team, RK Pachauri and L. A Meyer (Eds.)], edited by S Planton and C von Stechow (eds.) Mach, KJ, 11730. Geneva, Switzerland: IPCC

Jiang L, O’Neill BC (2017) Global urbanization projections for the shared socioeconomic pathways. Glob Environ Change 42:193-199. https://doi.org/10.1016/j.gloenvcha.2015.03.008

Jones B, O’Neill BC (2020). Global one-eighth degree population base year and projection grids based on the Shared Socioeconomic Pathways, Revision 01. Palisades, NY: NASA Socioeconomic Data and Applications Center (SEDAC). https://doi.org/10.7927/m30p-j498. Accessed 27 may 2020

Jurgilevich A, Räsänen A, Groundstroem F, Juhola S (2017) A systematic review of dynamics in climate risk and vulnerability assessments. Environ Res Lett 12:013002. https://doi.org/10.1088/1748-9326/aa5508

Kaivo-oja J, Luukkanen J, Wilenius M (2004) Defining alternative national-scale socio-economic and technological futures up to 2100 SRES scenarios for the case of Finland. Boreal Environ Res 9:109-125

Kc S, Lutz W (2017) The human core of the shared socioeconomic pathways: population scenarios by age, sex and level of education for all countries to 2100. Glob Environ Change 42:181-192. https://doi.org/10.1016/j. gloenvcha.2014.06.004

Kjellstrom T, Briggs D, Freyberg C, Lemke B, Otto M, Hyatt O (2016) Heat, human performance, and occupational health: a key issue for the assessment of global climate change impacts. Annu Rev Public Health 37:97-112. https://doi.org/10.1146/annurev-publhealth-032315-021740

Klein Rosenthal J, Kinney PL, Metzger KB (2014) Intra-urban vulnerability to heat-related mortality in New York City, 1997-2006. Health Place 30:45-60. https://doi.org/10.1016/j.healthplace.2014.07.014

Kok K, Pedde S, Gramberger M, Harrison PA, Holman IP (2018) New European socio-economic scenarios for climate change research: operationalising concepts to extend the shared socio-economic pathways. Reg Environ Change 19:643-654. https://doi.org/10.1007/s10113-018-1400-0

Kollanus V, Tiittanen P, Lanki T (2019) Mortality effect of heatwaves in Finland - factors affecting sensitivity. Environ Epidemiol 3:212-213. https://doi.org/10.1097/01.ee9.0000608180.41536.2c

Kuehn L, McCormick S (2017) Heat exposure and maternal health in the face of climate change. Int J Environ Res Public Health 14:853. https://doi.org/10.3390/ijerph14080853

Kyselý J, Plavcová E (2011) Declining impacts of hot spells on mortality in the Czech Republic, 1986-2009: adaptation to climate change? Clim Change 113:437-453. https://doi.org/10.1007/s10584-011-0358-4

Mannila S, Reuter A (2009) Social exclusion risks and their accumulation among Russian-speaking, ethnically Finnish and Estonian immigrants to Finland. J Ethn Migr Stud 35:939-956. https://doi.org/10.1080/ 13691830902957718

Marsha A, Sain SR, Heaton MJ, Monaghan AJ, Wilhelmi O (2016) Influences of climatic and population changes on heat-related mortality in Houston, Texas, USA. Clim Change 146:471-485. https://doi.org/10. 1007/s10584-016-1775-1

Miles V, Esau I (2020) Surface urban heat islands in 57 cities across different climates in northern Fennoscandia. Urban Clim 31:100575. https://doi.org/10.1016/j.uclim.2019.100575

Mora C, Dousset B, Caldwell IR, Powell FE, Geronimo RC, Bielecki CR, Trauernicht C (2017) Global risk of deadly heat. Nature Clim Change 7:501-506. https://doi.org/10.1038/nclimate3322

Nauels A, Rogelj J, Schleussner C, Meinshausen M, Mengel M (2017) Linking sea level rise and socioeconomic indicators under the shared socioeconomic pathways. Environ Res Lett 12:114002. https://doi.org/10.1088/ 1748-9326/aa92b6

Nilsson AE, Bay-Larsen I, Carlsen H, Van Oort B, Bjørkan M, Jylhä K, Van der Watt L (2017) Towards extended shared socioeconomic pathways: a combined participatory bottom-up and top-down methodology with results from the Barents Region. Glob Environ Change 45:124-132. https://doi.org/10.1016/j. gloenvcha.2017.06.001

Nishiura O, Tamura M, Fujimori S, Takahashi K, Takakura J, Hijioka Y (2020) An assessment of global macroeconomic impacts caused by sea level rise using the framework of shared socioeconomic pathways and representative concentration pathways. Sustainability 12:3737. https://doi.org/10.3390/su12093737

O'brien RM (2007) A caution regarding rules of thumb for variance inflation factors. Qual Quant 41:673-690. https://doi.org/10.1007/s11135-006-9018-6

O’Neill BC, Kriegler E, Riahi K, Ebi KL, Hallegatte S, Carter TR, Van Vuuren DP (2013) A new scenario framework for climate change research: the concept of shared socioeconomic pathways. Clim Change 122: 387-400. https://doi.org/10.1007/s10584-013-0905-2

O’Neill BC, Kriegler E, Ebi KL, Kemp-Benedict E, Riahi K, Rothman DS, Solecki W (2017) The roads ahead: narratives for shared socioeconomic pathways describing world futures in the 21st century. Glob Environ Change 42:169-180. https://doi.org/10.1016/j.gloenvcha.2015.01.004 
O’Neill BC, Carter TR, Ebi K, Harrison PA, Kemp-Benedict E, Kok K, Pichs-Madruga R (2020) Achievements and needs for the climate change scenario framework. Nat Clim Chang 10:1-11. https://oi.org/10.1038/ s41558-020-00952-0

Palinkas LA, Wong M (2020) Global climate change and mental health. Curr Opin Psychol 32:12-16. https://doi. org/10.1016/j.copsyc.2019.06.023

Pierce D (2019). ncdf4: Interface to Unidata netCDF (Version 4 or Earlier) Format Data Files. R package version 1.17. https://CRANR-project.org/package=ncdf4

R Core Team (2020) R: a language and environment for statistical computing. R Foundation for Statistical Computing, Vienna, Austria https://www.R-project.org/

Räisänen J, Räty O (2012) Projections of daily mean temperature variability in the future: cross-validation tests with ensembles regional climate simulations. Clim Dyn 41:1553-1568. https://doi.org/10.1007/s00382-012$1515-9$

Räsänen A, Heikkinen K, Piila N, Juhola S (2019) Zoning and weighting in urban heat island vulnerability and risk mapping in Helsinki, Finland. Reg Environ Change 19:1481-1493. https://doi.org/10.1007/s10113-01901491-x

Reckien D (2018) What is in an index? Construction method, data metric, and weighting scheme determine the outcome of composite social vulnerability indices in New York City. Reg Environ Change 18:1439-1451. https://doi.org/10.1007/s10113-017-1273-7

Reckien D, Creutzig F, Fernandez B, Lwasa S, Tovar-Restrepo M, Mcevoy D, Satterthwaite D (2017) Climate change, equity and the Sustainable Development Goals: an urban perspective. Environ Urban 29:159-182. https://doi.org/10.1177/0956247816677778

Rees P, Boden P, Dennett A, Stillwell J, Jasinska M, De Jong A, Ter Veer M (2010) Report on scenarios and a database of scenario drivers. EPSON DEMIFER Project Annex D6

Riahi K, Van Vuuren DP, Kriegler E, Edmonds J, O'neill BC, Fujimori S, Tavoni M (2017) The shared socioeconomic pathways and their energy, land use, and greenhouse gas emissions implications: an overview. Glob Environ Change 42:153-168. https://doi.org/10.1016/j.gloenvcha.2016.05.009

Robine JM, Cheung SLK, Le Roy S, Van Oyen H, Griffiths C, Michel JP, Herrmann FR (2008) Death toll exceeded 70,000 in Europe during the summer of 2003. CR Biol 331:171-178. https://doi.org/10.1016/j. crvi.2007.12.001

Rohat G (2018) Projecting drivers of human vulnerability under the shared socioeconomic pathways. Int J Environ Res Public Health 15:554. https://doi.org/10.3390/ijerph15030554

Rohat G, Flacke J, Dao H, Van Maarseveen M (2018) Co-use of existing scenario sets to extend and quantify the shared socioeconomic pathways. Clim Change 151:619-636. https://doi.org/10.1007/s10584-018-2318-8

Rohat G, Flacke J, Dosio A, Pedde S, Dao H, Van Maarseveen M (2019a) Influence of changes in socioeconomic and climatic conditions on future heat-related health challenges in Europe. Glob Planet Change 172: 45-59. https://doi.org/10.1016/j.gloplacha.2018.09.013

Rohat G, Wilhelmi O, Flacke J, Monaghan A, Gao J, Dao H, Van Maarseveen M (2019b) Characterizing the role of socioeconomic pathways in shaping future urban heat-related challenges. Sci Total Environ 695:133941. https://doi.org/10.1016/j.scitotenv.2019.133941

Ruosteenoja K, Jylhä K, Kämäräinen M (2016) Climate projections for Finland under the RCP forcing scenarios. Geophysica 51

Ruuhela R, Jylhä K, Lanki T, Tiittanen P, Matzarakis A (2017) Biometeorological assessment of mortality related to extreme temperatures in Helsinki region, Finland, 1972-2014. Int J Environ Res Public Health 14: 944. https://doi.org/10.3390/ijerph14080944

Ruuhela R, Hyvärinen O, Jylhä K (2018) Regional assessment of temperature-related mortality in Finland. Int J Environ Res Public Health 15:406. https://doi.org/10.3390/ijerph15030406

Ruuhela R, Votsis A, Kukkonen J, Jylhä K, Kankaanpää S, Perrels A (2021) Temperature-related mortality in helsinki compared to its surrounding region over two decades, with special emphasis on intensive heatwaves. Atmosphere 12:46. https://doi.org/10.3390/atmos12010046

Sellers S, Ebi KL (2017) Climate change and health under the shared socioeconomic pathway framework. Int J Environ Res Public Health 15:3. https://doi.org/10.3390/ijerph15010003

Shukla R, Gleixner S, Yalew AW, Schauberger B, Sietz D, Gornott C (2021) Dynamic vulnerability of smallholder agricultural systems in the face of climate change for Ethiopia. Enviro Res Lett 16:044007. https://doi.org/10.1088/1748-9326/abdb5c

Sohail H, Kollanus V, Tiittanen P, Schneider A, Lanki T (2020) Heat, heatwaves and cardiorespiratory hospital admissions in Helsinki, Finland. Int J Environ Res Public Health 17:7892. https://doi.org/10.3390/ ijerph17217892

Statistics Finland (2020). Paavo postal code area statistics. https://www.stat.fi/tup/paavo/index_en.html. Accessed 4 June 2020 
Terama E, Clarke E (2016). European regional - NUTS2 level - population projections with age structure across SSPs.10.6084/m9.figshare.3806478.v4 Accessed 15 August 2020

Terama E, Clarke E, Rounsevell MDA (2019) Modelling population structure in the context of urban land use change in Europe. Reg Environ Change 19:667-677. https://doi.org/10.1007/s10113-017-1194-5

Van Ruijven BJ, Levy MA, Agrawal A, Biermann F, Birkmann J, Carter TR, Schweizer VJ (2013) Enhancing the relevance of shared socioeconomic pathways for climate change impacts, adaptation and vulnerability research. Clim Change 122:481-494. https://doi.org/10.1007/s10584-013-0931-0

Van Vuuren DP, Edmonds J, Kainuma M, Riahi K, Thomson A, Hibbard K, Rose SK (2011) The representative concentration pathways: an overview. Clim Change 109:5-31. https://doi.org/10.1007/s10584-011-0148-Z

Vanos JK, Baldwin JW, Jay O, Ebi KL (2020) Simplicity lacks robustness when projecting heat-health outcomes in a changing climate. Nat Commun 11:1-5. https://doi.org/10.1038/s41467-020-19994-1

Wickham H (2011) The split-apply-combine strategy for data analysis. J Stat Softw 40:1-29 http://www.jstatsoft. org/v40/i01/

Zandersen M, Olesen JE, Jabloun M, Andersen HE, Hyytiäinen K, Pihlainen S, Sihvonen M (2016). D1.1 Report on regionalized SSPs and RCPs resulting in a coherent set of climate and socioeconomic scenarios for the Baltic Sea region.

Zhang W, Zheng C, Chen F (2019) Mapping heat-related health risks of elderly citizens in mountainous area: a case study of Chongqing, China. Sci Total Environ 663:852-866. https://doi.org/10.1016/j.scitotenv.2019. 01.240

Publisher's note Springer Nature remains neutral with regard to jurisdictional claims in published maps and institutional affiliations.

\section{Affiliations}

\section{Armand Landreau $^{1,2} \cdot$ Sirkku Juhola ${ }^{2} \cdot$ Alexandra Jurgilevich $^{2} \cdot$ Aleksi Räsänen $^{2,3}$}

1 École polytechnique, Palaiseau, France

2 Ecosystems and Environment Research Programme, University of Helsinki, Helsinki, Finland

3 Natural Resources Institute Finland (Luke), Oulu, Finland 